\title{
Determinants of FLFP and its impact on economic growth evidence from: Egypt, Germany, and Pakistan
}

\begin{abstract}
The main aim of the following paper is discussing the gender wage discrimination and the impact of an increase in the female labor force participation on economic growth. A comparative study between Egypt and Germany is presented in order to determine the conditions of the female labor market and its wide gender wage gap (GWG) in both countries in addition to its driving forces. Moreover, the reader would be capable of determining how each of Egypt and Germany deal with the problem of wide GWG through previously implemented initiatives and why didn't they succeed. Eventually, the reader would be capable of concluding the result of the research paper, which asserts that the increase in FLFP enhances economic growth. This will be determined through a case study on Pakistan which proves the paper's stance.
\end{abstract}

Volume 3 Issue 2 - 2019

\author{
Doaa Salman Abdou, Dina Shalaby \\ Department of Economics, University of Modern Sciences \& \\ Arts, Egypt
}

Correspondence: Doaa Salman Abdou, Professor of Economics, Head of Economics Department Vice Dean for Community Services \& Environmental Affairs Modern Sciences \& Arts University (MSA), Egypt, Email Dsalman@msa.eun.eg

Received: January 0I, 2017| Published: March 27, 2019

Keywords: gender wage gap, female labor participation, growth

\section{Introduction}

Gender discrimination is a widely spread issue across numerous countries all over the globe, no matter how developed and civilized a country is. In gender discrimination, females are the ones who usually suffer from this inequality as they encounter it much more than men do. Unfortunately, females encounter discrimination in several sectors; Education, career, and politics. When clarifying the concept of female's career discrimination, it is worth mentioning that it comes in several forms such as fewer employment opportunities, low wages, lower work positions, and sometimes even inferior treatments at workplace. This discrimination highly affects the females' participation in the labor force. When observing the statistical evidence concerning the majority countries, it can be perceived that global female participation rate in the labor force only represents $39.3 \%$ of the total labor force; based on statistical data extracted from The World Bank. Furthermore, another indication for the gender inequality is "Gender Gap index" which includes 144 countries with rankings regarding how equal they are; top ranked countries are the most equal and vice Versa.

The question here is does the participation of females in the labor force has an impact on the economic growth? Does their participation improve, worsen, or do not even influence the economy as a whole? These questions must be deeply thought about and figured out in order to what actions should be take in order to enhance economic growth, which is the main aim for all countries. Despite the different opinions concerning the impact of increase in female participation in labor force on economic growth and the fact that till this day, a very high percentage of women still suffer from employment discrimination and wag segregation, it was proven in several empirical cases that an increase in female labor force participation does enhance economic growth and GDP. One of the cases that highly demonstrate the stance that female participation in labor force enhances economic growth is Pakistan; Thus, it was taken as a case study in the paper to prove my stance. Additionally, Egypt and Germany are taken as examples for females' employment discrimination. The following comparative study will begin by discussing the different point of views regarding the impact of the increase in the rate of females' labor force participation on economic growth through the literature review. Moreover, this will be followed by deeply discussing and comparing between women employment discrimination and wage segregation in Egypt and Germany then a case study about the story behind the enhancement of Pakistan's economic growth will be presented. Eventually, the comparative study will be ended by the conclusion part in which all the main ideas of the paper will be comprehended to be easier for the reader to organize the main ideas and thoughts.

\section{Literature review}

In order to emphasize whether the increase in female participation in an economy's labor force, a wider look had to be taken on the different perspectives regarding the issue. Even though one would think that any increase in the number of labor force would promote economic growth as a result of an increase in domestic production, several opinions declare the opposing sentiment when it comes to the increase of the participation of "females" in the labor force. In other words, some perspectives support the stance that participation of females in the labor force has a negative impact on economic growth. One of the very few perspectives that looked at the impact of women participation in labor force on economic growth in terms of productivity and time management is the "Time Allocation" theory. Time allocation theory was developed by Becker, Heckman and Killings worth in which they argued that since women have many responsibilities such as children and house management, they suffer from a significant problem of time management which results in lack of concentration at work. Consequently, the overall productivity declines and the economic growth slows downs so there is a negative relation between economic growth and females labor force participation.

As stated by Goldin, the increase in female participation rate in a country is negatively related to economic development and growth. Low developing countries that mainly rely on the agricultural sector and lack industrialization have high female labor force participation rate in which they take care of their family's lands; Even though this is an unpaid job, it is still counted in the labor force. Goldin claimed that in order to reach economic growth, structural changes in a country must take place; in terms of transforming the economy from an agricultural to an industrial one. ${ }^{1}$ As a result, this structural change leads to a decline in the female labor participation as it is now harder for women to keep up with their duties. However, Goldin also claimed that when an economy reaches growth, with low female labor force participation, women start to get back to their previous important position in the newly industrialized economy with favorable employment chances. ${ }^{1}$ Contradictory to both ${ }^{2}$ stated that female's 
labor increases the economy's overall productivity which reflects on economic and GDP growth. Tansel argued that an increase in female labor force participation highly promotes efficiency and development in a country. Consequently, females could definitely be the driving force towards growth; hence, countries should consider encouraging the participation of females in labor force for the benefit of their economies. ${ }^{3}$

Moving to a somehow different perspective, Gaddis declared that there is no apparent relationship between female labor force participation and economic growth. This stance is based on a previous study that closely examined the influence of female labor force participation on GDP which revealed that the economic growth depends on several factors such as the quantity and quality of human resource in a country, doesn't matter if they include women or not, technology, natural resources etc... Consequently, Gaddis and Klasen believe that economic growth doesn't depend on the increase in female labor force participation. ${ }^{1}$

\section{Females' participation in the Egyptian labor market}

Egypt is a developing country with a GDP of \$235.4 billion that grows at $4.18 \%$ in 2017, according to the World Bank Data. Egyptians are known for their attachment to their own historical cultural and religious beliefs. Consequently, Egypt's culture shapes the role of a woman within the country as the housewife who has no obligations in life other than taking care of her house, kids, and husband which reflects that women financially rely on their men. This belief is common in most of the Arab countries and it is worth mentioning that Egypt, Tunisia, Morocco, and Jordan are ranked the lowest, globally, when it comes to measuring the female labor force participation. ${ }^{4}$ According to the Center for Economic and Social Rights (2013), Egypt encounters very low levels of female participation in the labor market; varying between $20 \%-25 \%$ from the total labor force in the 2000s. ${ }^{4}$ Later according to the "World Economic Forum", despite all the economic reforms that are taking place in Egypt, the FLFP remains low at $23.1 \%$ in year 2017. Additionally, Egypt has a huge problem of wide gender wage gap, with a rank of 134 from 144 countries and this problem remains challenging till this day with regards to economic growth and development in Egypt.

Going back to significant events that highly influenced the FLFP in Egypt, it is worth mentioning the impact of oil boom that took place in the 1970s. Moghadam argued that oil-related jobs require men not women due to the unsatisfactory working conditions in the oil rigs that are somehow risky and can possibly be intolerable by females. Consequently, the oil boom period in the 1970s was one of the aspects that resulted in limiting the supply of female labor; women who participated in the labor force at that time were viewed as "defeminized" because most of the jobs available were mendominated ones. ${ }^{5}$

Despite their minimal participation in the Egyptian labor force, Women represent a higher percentage of the labor force participation than men in the state-owned sectors. Nevertheless, men workers are still the majority in the private sectors. As a result, the growth of informal activity among women in Egypt takes place; this is due to the very low wages of public sectors, where the majority of women work in, and the lack of women employment in private sectors, which give much higher wages compared to the public ones. ${ }^{4}$

Figure 1 demonstrates the different GWG in both the private and public sectors and it can be observed that the higher percentage of
GWG lies in the private sector. Contradictory to the fact that Egypt has a very wide GPG, women in public sectors not only represent a higher employment percentage than men but also there is a wide gender wage gap in favor to woman not men. To be more specific, it was estimated in year 2014 that the weekly wage of men in the public sector and public sector businesses amounted 1008 EGP yet the weekly wage of women amounted 1161 EGP. These wages reflect how the gender pay gap can sometimes be in favor to woman as the GWG at the same period, year 2014, represented $15.18 \%{ }^{6}$

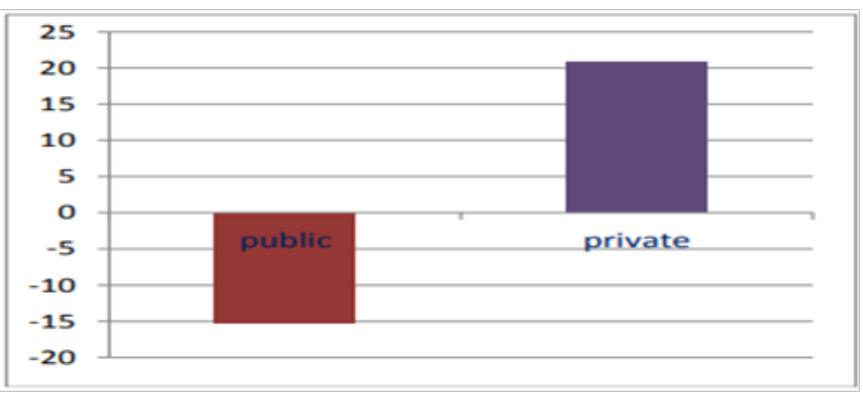

Figure I The GWG\% according to Sectors in Egypt.

Table 1 clarifies the GWG\% among different sectors and it could be observed that we couldn't ignore the reality that when the three of "public sector, public business sector, and private sector" combined; the overall GWG, amounting $8.7 \%$, is in favor of men. This percentage of the overall GWG in Egypt indicates how high the GWG is in the private sector within the country as it highly exceeds that of the public sector in a very significant way. Yet, there are some jobs in the public sectors that pay men higher than women such as education, with the widest pay gap at $86.9 \%$ followed by social work and healthcare representing $35.5 \%$, manufacturing industries, at $24.9 \%$, and the least GWG at $12.2 \%$ in the agricultural sector. ${ }^{6}$ The previously stated percentages of GWG in these sectors are in favor of males because it is believed that males attain higher educational levels at these specific fields; this reflects how education plays an extremely important role when it comes to determining the GWG. On the other hand, it is worth noting that the GWG in other jobs in the public sectors such as arts and creativity, electricity supply, services, and construction is highly in favor of females; amounting $45.9 \%, 19.5 \%, 51.6 \%$, and $15 \%$ respectively. Also, this is due to the higher educational levels of females in these sectors. ${ }^{6}$

Table I The GPG\% Among Different Sectors in Egypt

\begin{tabular}{llll}
\hline & Male & Female & GPG\% \\
\hline I- Managers, senior officials and legislators & 1879 & 2186 & -16.3 \\
2- Professionals & 1012 & 775 & 23.4 \\
3- Technicians and associative professionals & 829 & 521 & 37.2 \\
4- Clears & 846 & 778 & 8 \\
5- Service and sales workers & 546 & 526 & 3.7 \\
6- Skilled agricultural and fishery workers & 508 & 420 & 17.3 \\
7- craft and related trades workers & 570 & 360 & 36.8 \\
8- Plant and machine Operators and & 514 & 302 & 41.2 \\
assemblers & 588 & 289 & 50.9 \\
9- Elementary occupations & 817 & 746 & 8.7 \\
Total & & & \\
\hline
\end{tabular}

Additionally, women's marital status influences the FLFP in the private sector. Assaad and El-Hamidi stated that women tend to resign 
when they get married only if they work in private sector; on the other hand, newly married women resume working normally if they work in public sector. Consequently, women start looking for another source of income, so they find no other choice than operating in the informal sector and this hinders Egypt's economic growth; women working in informal sectors amount an average of $50 \%$ of the total female participation in the Egyptian labor force. ${ }^{4}$

When discussing the female labor force participation in the Egyptian labor market, it is worth mentioning that the 25th January revolution, year 2011, played a considerable role in a general drop in the labor force participation (men and women) due to the political and economic instability at that time. In Egypt, the rate of women participation in the labor force contradicts the ordinary as it is notable that there is a direct relationship between education and employment as when women are more educated, the FLFP inclines. Nonetheless, according to the UNDP and Ministry of Economic Development (2010), when Egypt witnessed a significant improvement in the women education; starting the period between 2008-09 as females' school enrollment ratio reached $96 \%$ the FLFP was not only still low but also nearly all the unemployed females were educated. ${ }^{4}$

\section{Factors driving wide gender pay gap in Egypt}

The factors leading to wide wage gap in Egypt is somehow different that those of Germany as in Germany the causes of GWG are ordinary and very predictable; yet, in Egypt, the factors do not only revolve around the women's obligations but also culture plays an extremely important role when it comes to determining the females' participation in the labor force or wages. As it was mentioned at the beginning, the major factor that influences the employment of women within Egypt goes back to the Egyptian culture that men are the dominant figure in the society. The major factor leading to wide GWG is that the economic activities of women are underestimated. This means that no matter how women are successful in their jobs or even in knowledge as it is always thought that women do not have enough knowledge and they are usually not as capable as men in participating in certain activities. In other words, the top place in the social structure is always dominated by men not women. ${ }^{7}$

Another factor that leads to wide GWG in Egypt roots back to the high reliance of women on men in the Egyptian society which is a form of men's dominance. In Egypt, the girl is always responsible from either her father or brother and when she grows older the woman becomes responsible from her husband, which reflects how the men in general are considered the backbone for women. This is a common phenomenon in Egypt; thus, women are undoubtedly financially dependent on their men no matter how old they get. This phenomenon has a considerable influence on the level of wages women earn as their wage is considered as a secondary income because the primary one is that of men; consequently, the higher level of wages goes to men because it will eventually go to their daughter or wife.

Additionally, in Egypt and most of the countries, the salary level is highly and mainly dependent on the number of years of experience. In the married women's case, which represent the majority of women in Egypt, quit their jobs for maternity and this act highly affects their years of experience and their capability of finding new job after several years later. As a result, if they found a new job afterwards, they will start from the beginning with low wage levels. Besides, women's maternity obligations also act as an obstacle regarding the employment in private sector. Private business owners aim for committed and efficient workers who aim add something beneficial to their businesses and generate profits, so women are considered risky to those business owners because the majority of them will need to eventually leave for either maternity or family obligations. Eventually, they do not have a choice but working in low-paid jobs such as secretarial and nursing or day care business, mostly in public sector, to generate any kind of income even if it's a low one. Eventually, Egyptian women highly lack awareness about their social rights mainly due to their parents who were also raised that men are the dominant figure and they do not aware their daughters about their rights, they only mention their responsibilities toward their husband and family. Hence, the problem of wide wage gap in Egypt is still persistent because Egyptian women are incapable to even ask for their right in the society or the workplace. Besides, Egyptian women, unfortunately, lack the power of speaking up even if they are aware of their rights due to their insignificant participation in the trade unions and parliament that are considered very powerful methods to speak up for rights. ${ }^{7}$

\section{Previous initiatives to reduce GWG in Egypt}

Egypt has exerted notable efforts to enhance the status of the Egyptian women through implementing a series of actions that aimed to enable and empower them politically, economically and in social areas. These actions included the elimination of all forms of discrimination against women, in addition to implementing the necessary legislative reforms that serves this objective, as well as taking actions aimed at changing the biased societal values and concepts that have negative implications on women and their role as an active player in the development of the nation. In that, the State believes that global development cannot be achieved without the active participation of women who practically constitute half of the society, accordingly the State adopts policies that strengthen their economic, social, cultural and political participation in all its forms. ${ }^{6}$ In response to a proposal made by the National Council for women, Equal Opportunity Units were created within the different ministries in Egypt. These offices directly follow the ministers' office and their main function is to focus on the constitutional equality between men and women at the workplace and address any discriminatory employment practices against women and provide legal awareness programs and support the rights of working women and help them get the necessary training and promotion opportunities. The Equal Opportunities Unit at the Ministry of finance, in cooperation with the National Council for women, work on spreading the concept of gender responsive budgeting in collaboration with the United Nations Fund for women (UNIFEM), and among the workers of the Ministry of Finance and the officials responsible for preparing the draft of the state budget. $^{?}$

Additionally, Law No. 12 of 2003, which included a special chapter on the employment of women, was released, stating that women shall receive equal pay for the same job as men, and prohibited employing them in jobs that are physically hard, dangerous or harmful by nature, moreover, women may not be employed at night, except by decree issued by the Minister of Manpower, the law also obliges the private sector and private businesses to provide protection to their women employees during pregnancy, childbirth, and allow for maternity leave, child care, and that they may not be dismissed from work due to any reason pertaining to motherhood and pregnancy. ${ }^{8}$

There are several initiatives to empower women in the Egyptian society; however, unfortunately, the concentration on narrowing the gender wage gap was insignificant. Despite the effort to enhance the role of women within the Egyptian society, still the problem of 
gender inequality is hard to overcome due to several factors. Illiteracy constitute an obstacle to the advancement of the status of women in society and the understanding of their rights, roles and reality and the importance of exercising their duties on fuller form, although there is a slight improvement in the low literacy rate among women from $37.3 \%$ in 2006 to $32.5 \%$ in 2012 ; yet, this percentage is still very high. On top of that, the negative cultural traditions against women, supported by the religious biased conceptions remain the most important challenges facing the Egyptian women. Cultural legacies in some communities prevent the ownership or possession of land or property by women, in violation to the provisions of the "Islamic Sharia". ${ }^{8}$

\section{Females' participation in the German labor force}

It is known that Germany is a developed country, with a very high GDP reaching US\$ 3.677 trillion in 2017 with growth at $2.22 \%$, and more civilized than Egypt when it comes to employment gender equality; however, Germany's gender pay-gap is still considered as one of the widest among the European countries, only lower than Czech Republic and Estonia. In Germany the case is different from Egypt as in Egypt the participation of females represents a very low percentage of the total Egyptian labor force, $23.1 \%$ as it was previously mention, followed by a very wide gender wage gap due to the very low empowerment of women in the Egyptian culture. ${ }^{9}$

On the other hand, Females employment in Germany accounts $46.5 \%$, which is a very satisfactory percentage when compared to Egypt. Germany appreciates women's role in the society and women are actually responsible for very important governmental positions in Germany, most accurate example is the prime minister "Angela Merkel" so the gender gap index which reflects the participation of women in economic and political activities besides the educational and health benefits; yet the problem with gender inequality in Germany is summed up in the wide wage gap between males and females. ${ }^{9}$

As Figure 2 reflects, Germany has one of the highest Gender Pay Gap as it ranks as one of the worst 12 European countries when it comes to equality regarding gender pay in sectors. The employment of females in Germany is concentrated in the service sectors; which is less likely get affected by any fluctuations happening in the economy and also because Germany is an economically and a politically stable country, it doesn't affect the employment of females. Yet, women still earn $25 \%$ less than men do; this wage gap is considered unsatisfactory when compared to the European countries with the same development and growth levels. Consequently, Germany is ranked as the 7th worst gender wage equality among European countries. ${ }^{9}$

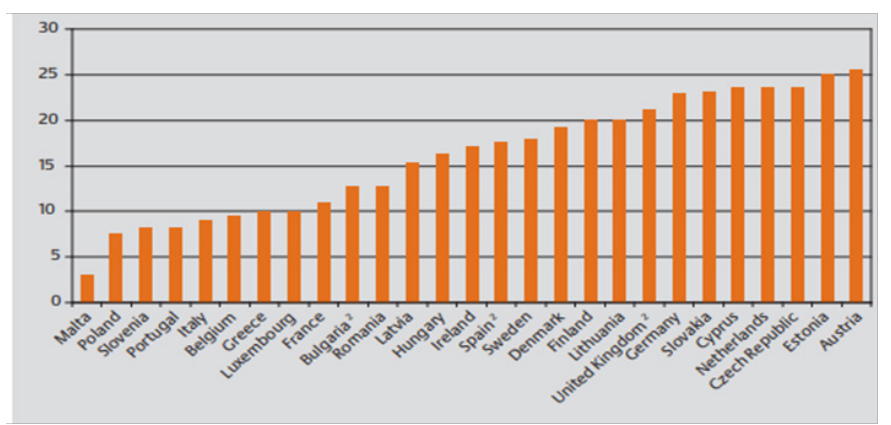

Figure 2 The Position of Germany's GWG among European countries.

In Germany, the fields that the gender pay gap highly exists are the healthcare and financial sectors as it exceeded the average pay gap. For instance, in the healthcare sector such as hospitals, pharmacies, and medicine companies the Gender Wage Gap in Germany represents $25 \%$ which is highly above the average Gender Wage Gap. Additionally, women in the financial sectors in Germany such as banks and stock exchanges highly suffer from a very high GWG; reaching up to $29.9 \%$. Nevertheless, it's surprising to figure out that the share of female employment represents a very high percentage in both sectors. ${ }^{10}$

The majority of the employees in the healthcare sector in Germany are females meaning that they actually dominate the healthcare sector as their employment represents $78 \%$, which is considered an extremely high percentage of employment relative to the share of men in the sector. Furthermore, the same scenario applies to the financial sector in Germany but not with as high female employment percentage as in the healthcare sector. Women employment in the financial sector represents $52 \%$ which represents a somewhat higher percentage than men employment; however, this doesn't reflect that they dominate the financial sector. ${ }^{10}$

\section{Factors driving wide gender pay gap in Germany}

It is totally obvious that females in the German labor market suffer from a vertical segregation. As a result, a study was conducted in Germany by "EU Commission, the Federal Ministry of Family Affairs, Senior Citizens, Women and Youth" for the purpose of determining the factors leading to a wide gender wage gap in order to be capable of solving the problem. From reviewing the causes, it could be figured out that the causes of wide wage gap in Germany are ordinary and similar to the general causes leading to the problem. First cause to the wide wage gap in Germany is that, despite the fact that women are responsible for very important governmental positions and are actually empowered in the society, the majority of women are employed in low-paid and part-time jobs. These low paid jobs result from the incapability of German women to hold managerial posts as most of the managers in companies are men not woman. This lies in the problem of hierarchical levels within corporation in Germany which guarantees men higher and more important posts than women. This results in women getting paid lower than men due to their low paid jobs. Nevertheless, this distorted hierarchal structure in Germany is improving through time. ${ }^{11}$

Moreover, women tend to sacrifice their working hours and jobs for managing their responsibilities toward their families as women who intend to build families put less effort in attaining good education or training to enhance their skills. This phenomenon is very common among women in different countries no matter how developed a country is. Consequently, lower educational levels in addition to fewer working hours eventually leads to women earning less wage than men do. ${ }^{11}$ Figure 3 represents the average gender wage gap in Germany according to age levels. It could be observed that the fresh graduates in Germany are subjected to minimal wage discrimination. Yet, as females get subjected to more and more wage discrimination as they grow older in age. It is believed that these wide wage gaps percentages go back to the basis that women employees who attained their higher degree education in Germany at the same year represented $26 \%{ }^{11}$

The percentage of educational attainment for females is relatively low in comparable with that of men employees which amounted $34 \%$. However, when it comes to measuring the educational level of girls with lower age ranges, it could be figured out that girls in high schools exceed boys with regards to educational levels; nevertheless, females' college graduates in the same year represented $49 \%$ while males represented $56 \% .^{11}$ 


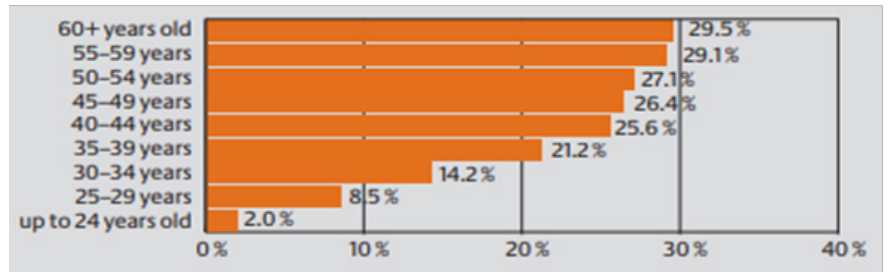

Figure 3 Illustrates the Gender Pay Gap in Germany Based on Age Level.

\section{Previous initiatives to reduce GWG in Germany}

Even though the wide gender pay gap still exists within Germany, it is worth mentioning that the country had initiated several policies and ideas for the purpose of reducing the considerable pay gap. One of the very well-known policies that help in vanishing the problem of Gender wage discrimination is "The Equal Pay Act". Consequently, Germany began with organizing an equal pay day in the year 2008 by "The Business and Professional Women" organization, which is inspired from that of the USA, that takes place on the 18th of March in Germany. Nonetheless, the equal pay day's main aim is only spreading awareness regarding the gender wage gap and how is it unethical and should vanish so in reality, that day did not really help in solving the problem of wide pay gap in Germany. Yet, in the equal pay day of year 2015, the Minister for Women and Family Affairs, announced that the Government will release a new legal act in which income structures are more transparent; Law on Pay Transparency. That act would lead Companies to be asked to detect existing discrimination structures and mechanisms and together with collective bargaining partners to develop measures to close the gender pay gap. Furthermore, each employee will be entitled to hear about his/her job grading. ${ }^{12}$

Besides, since Germany is a technologically advanced country, one of the initiatives to reduce GWG took place through the internet. That tool for more wage transparency is the wage calculator, "Wage Mirror", which has been initiated by the Institute for Social and Economic Research (WSI) in 2004. It provides data on wages and income which have been collected through online evaluation. By using the Wage Mirror tool, the upper hands or authorities in Germany, such as government and ministries, would be capable of communicating with employees and noticing if there is a gender pay gap or not and by how much. ${ }^{12}$ In addition, in year 2009, the Ministry for Families, seniors, Women and Youth launched another tool "Logib-D" (Lohng leichheit im Betrieb-Deutschland) which is a free internet tool that enables companies to analyze their earnings structure concerning gender on a voluntary basis. Logib-D calculates which part of the gender pay gap in the company is due to years of vocational training, years of work life, hierarchical position, part time, size of team and gender. That initiative could be also counted as part of the pay transparency law. ${ }^{12}$

Moreover, unions have also initiated some equal pay initiatives; in 2014, The Food, Beverages and Catering Industry Trade Union (NGG) had put a plan to check all collective agreements for provisions with hidden discriminatory effects for women and part time workers. They wanted to raise awareness for these mechanisms among members of bargaining commissions. Also, in the same year, ver.di (German Trade Union) had launched a campaign to upgrade social and teaching occupations. They claimed a 10\%-increase of their wages and a higher valuation of the work that is done. Another project is called "Pflege 3000" (Care 3000) and aims at wages not under 3000 Euros for a qualified full-time worker in the nursing care sector. Furthermore ver. di took part in a funding program financed by the EU and the Federal government, called "Gleichstellen" (Treat Equally). The project aimed at improving working conditions for women and men through branch-oriented equality policies. Furthermore, the latest initiative that Germany had implemented was the "Wage Transparency Law" of 2016 which aimed to allow women to ask employers to provide information about average rates of pay for men and women in specific tasks. ${ }^{13}$

By all those previously implemented laws, Germany should've been free of gender wage gap; however, the problem still exists until now. The Transparency Law, for instance, applies only to large companies with more than 200 employees. And at the upper levels of the corporate ladder, it is very difficult to identify enough male and female peers for comparison. Since 2015, German law has mandated that the supervisory boards of some 100 very large companies be at least 30 percent female. It stands to reason that the more women occupy top positions in companies, the higher the average woman's wage will be in Germany. ${ }^{13}$

\section{The increase in FLFP led to increase in economic growth; Pakistan}

\section{History of females' labor market in Pakistan}

Historically, the time that Pakistan was part of the India, due to the Muslim community influence in the 19th century women was forced to wear the "purdah". The purdah was meant to isolate men and women social contact. The first empowering women movement was brought about by the reformer Syed Ahmad Khan. He argued that women should have equal education opportunities as men and advocated for female literacy. Muhammad Ali Jinnah, the founder of Pakistan continued this vision. He brought his sister Fatima Jinnah to the political front as a role model. Inspired by Fatima Jinnah many women's organizations and groups established, especially in the urban areas of Pakistan. ${ }^{14}$ Later, in 1947, after the independence of Pakistan, women were entitled the right to vote under the Pakistan Ordinance. They were reaffirmed and finally voted in the 1956 elections under the interim constitution. In 1956 Pakistan had a reservation of seats for women in the parliament. Nevertheless, Pakistan due to strong cultural norms and religious beliefs still could not completely remove all obstacles and gender inequality persists in all areas. ${ }^{14}$ The inequalities such as the education and employment gap and limited women's properties compared to men pointing to the fact that despite the efforts the gap persists. The culture of Pakistan is still patriarchal and the percentage of women participating to the paid work is extremely low $(24 \%)$.

\section{FLFP and economic growth in Pakistan}

Pakistan was chosen to be examined concerning the influence of an increase in female participation in the labor force on economic growth. Firstly, a general background about the female labor force in Pakistan is needed in order to help in taking a wider look on the situation. Staring from the 19th century, the majority of the Pakistani women did not engage in paid jobs and the minority of women who were employed in paid jobs mainly consisted of single females with young ages who still do not have family obligations. Consequently, at that time, marriage was considered a factor that prevents women from working; the few married women who had jobs were mostly in the sectors of either textiles or house maids. ${ }^{15} \mathrm{After}$ then, the structure of female labor force started changing starting from year 1930 when the Pakistani service sector started nourishing following an increase in office work. As a result, the Pakistani labor market demanded more 
female labor. Moreover, modern technology started to take place at that time in Pakistan, electricity in specific, which was considered satisfactory for females because it helped in reducing the unpaid work that they used to get engaged in and replacing it with paid work. ${ }^{15}$ Later in Pakistan, around the 1950s-1970s, women started to get concentrated in educational sectors such as schools and libraries in addition to some minor positions in health sectors such as nurses. At that time, the Pakistani women started to have a position in the society and their participation in the labor force started increasing dramatically. One of the major causes behind the significant growth of FLFP in Pakistan, reaching up to $75 \%$ compared to $40 \%$ growth rate in the 1970s, is the enhancement of the educational level of Pakistani females in the 1970s-1990s; this reflects how high educational levels for females have a direct effect on the female employment within countries. ${ }^{15}$

At the time where the Pakistani female labor forces experienced a significant enhancement, especially in the 1990s. This was followed by an improvement in the Pakistani GDP growth; amounting 4.04\% annually, according to statistical data extracted from the World Bank between the period of 1990-2013. Additionally, the highest GDP growth that Pakistan had experienced took place in year 2017 and amounted $5.7 \%$ and the same year coincides with the highest percentage of female participation in the Pakistani labor force. ${ }^{15}$ The following figure will clarify this positive relationship more throughout different consecutive years. As Figure 4 reflects the percentage of Pakistan's female's participation in the labor force in addition to Pakistan's GDP growth starting from the 1990s till year 2017. It can be observed from the above bar chart that there is a positive relationship between the increase in female labor force participation in Pakistan with the country's GDP growth. The shorter bars represent the annual percentage of Pakistan's GDP growth while the taller ones represent the female labor force; the positive relationship between both variables is clear because the increase in female's participation $\%$ of the labor force is followed by an increase in GDP growth and thus, economic growth especially in the year 1990, reaching $13.7 \%$, and years starting from 2011 until 2017). ${ }^{14}$

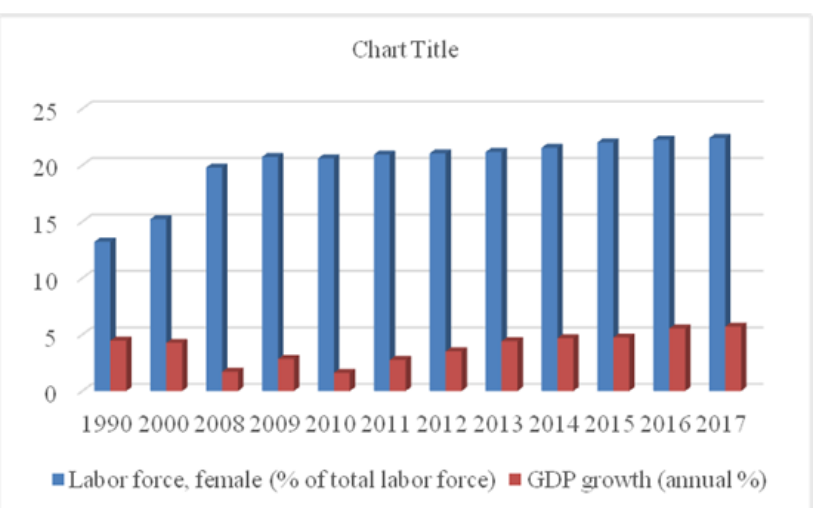

Figure 4 The relationship between Female Labor Force and GDP growth in Pakistan.

Moreover, years from 2000 until 2007, Pakistan have experienced a comparatively improved growth in its economy, average growth rate of $5.1 \%$, and this also marked a period of an increased participation of females in the Pakistani labor force. Nevertheless, this does not neglect the fact that Pakistani females still suffer from high illiteracy rates during recent years and the gender employment discrimination is still persistent in the Pakistani market. To be more specific, females' illiteracy was concrete more in Pakistan's rural areas. Moreover, Pakistan still lags far behind in comparison to other countries. A factor that needs to be considered over here is that of Islam and religious belief of Muslims in Pakistan that women should stay at home and observe "purdah" and the gender gap in education. Female to male literacy rate was 58.7. ${ }^{14}$ Nonetheless, Pakistan did not really encounter significant economic growth since in the period of the 90 's where the service sector took placed and FLFP highly improved. The unemployment level of Pakistan in 2012-2013 stood around $6.54 \%$ on average. Female unemployment was higher than men unemployment level, standing at $9.19 \%$ which could be another factor worth considering why female labor force participation is low. ${ }^{14} \mathrm{It}$ can be observed from Table 2 that there is a significant Gender Wage Gap that takes place in Pakistan even after the Female participation improved in the Pakistani labor force. Pakistan is close to Egypt in this case, as the culture and social norms are the major factors that arise the concept of gender wage discrimination within the country.

Table 2 GWG in Pakistan (2010-13)

\begin{tabular}{lll}
\hline $\begin{array}{l}\text { Average wage in } \\
\text { Rupees }\end{array}$ & 2010 - I I & 20 I 2-I3 \\
\cline { 2 - 3 } & Total Male Female & Total Male Female \\
\hline Total & 9715 I02II 6422 & I 2118 I2804 7869 \\
\hline
\end{tabular}

\section{Econometric model}

The following econometric model illustrates the factors that influence the factors that affect FLFP in Pakistan:

Female labor force participation regressed on macro variables provided by the previous studies on micro and macro determinant of female labor force participation. Such as real GDP per capita, female literacy rate, fertility rate and unemployment rates. The model is as follows:

\section{$\mathrm{FLFP}=\mathrm{B} 0+\mathrm{B} 1 * \mathrm{LGDP}+\mathrm{B} 2 * 1 \mathrm{lit}+\mathrm{B} 3 * \mathrm{Fer}+\mathrm{B} 4 *$ Une $+\mathrm{B} 5+\varepsilon$}

It can be observed that the dependent variable in the above econometric model is the Female Labor Force Participation Rate while the independent variables are GDP, Lit (Literacy Rate), Fer (Fertility Rate), and Une (Unemployment Rate). ${ }^{14}$

\section{Conclusion}

The paper critically analyzed the concept of Gender Wage Gap and the Female Labor force Participation effect on the economic growth. The comparative study included Egypt and Germany as they are totally different regarding their development and advancement level. However, both of them have a significant problem regarding a wide gender wage gap. The case of Egypt is very expected as Egypt is known for its cultural norms that assert the dominance of men over women, so Egyptian women not only suffer from wage discrimination but also from notable employment discrimination which hinders women's ability to participate in the Egyptian labor market. On the other hand, the case of Germany is very questionable as German women are known for their empowerment and their significant role in the country, yet they still suffer from wage discrimination due to very ordinary factors such as maternity obligations etc. It was believed that there is a significant relationship between the rate of female participation rate in the labor force and the gender wage gap. Nevertheless, Germany proved that there is no exact relationship between both variables. Both of Egypt and Germany had implemented several policies and laws in order to vanish or, at least, reduce the gender wage gap. Unfortunately, 
those laws showed little improvement, but we cannot consider them as permanent solutions as the problem still exists. This means that no matter how developed and big a country is, such as Germany, it could still be incapable of solving such conflicts.

Eventually, Pakistan was chosen as a case study to measure the influence of the increase in female participation in the labor force. Even though, Pakistan is an underdeveloped and poor country with slow economic growth, when the service sector started to take place in the period of 90's leading to the enhancement of female participation in the labor market. It resulted in an improvement in the GDP growth. Hence It could be figured out that the increase in female participation in the labor force truly leads to economic growth within countries.

I recommend that there are different policies that could be implemented to enhance the females' participation in the labor force to promote economic growth. Some of these policies could be the development of economic programs, projects and budgets from a gender perspective, diversify and enrich the economic and social training options available to women and work through a flexible system of partial and temporary work, or work from home or vocational distance training and e-marketing. On top of that, a review of national legislation, including equal pay for men to achieve equality in pay, bonuses and opportunities for rehabilitation and training, especially in the private sector is really needed.

\section{Acknowledgments}

None.

\section{Conflicts of interest}

The author declares there is no conflict of interest.

\section{References}

1. Rahul L, Swaminathan H. Economic growth and female labour force participation in India. Center for International Development at Hardward University.2013. 54 p.

2. Tsani S, Paroussos L, Fragiadakis C, et al. Female Labour Force Participation and Economic Development in Southern Mediterranean
Countries: What Scenarios for 2030?. Europe: MEDPRO Technical Report No. 19; 2012. 21 p.

3. Mollet JA. Female labour force participation and economic development in West Papua. Cambridge Scholars Publishing; 2011. 265 p.

4. Nazier H, Ramadan R. Women's participation in labor market in Egypt: Constraints and opportunities. Working Paper 999. 2016. 31 p.

5. Hendy R. Women's participation in the Egyptian labor market: 19982012. Egypt: The Egyptian Labor Market in an Era of Revolution; 2015.16 p.

6. Mohamed AKA. An Analysis of the Gender Pay Gap in the Egyptian Labour Market. 2015. 32 p.

7. Hosney SH. Factors influencing female labor force participation in Egypt and Germany: A comparative study. Germany: SOE Papers on Multidisciplinary Panel Data Research; 2016. 75 p.

8. Kamal H. Inserting women's rights in the Egyptian constitution: personal reflections. Journal for Cultural Research. 2015;19(2):150 161.

9. Weinkopf C. Women's employment in Germany. Revue de l'OFCE. 2014;(2):189-214.

10. Wrohlich K. Gender pay gap varies greatly by occupation. DIW Economic Bulletin. 2017;7(43):429-435.

11. Dustmann C, Ludsteck J, Schönberg U. Revisiting the German wage structure. The Quarterly Journal of Economics. 2009;124(2):843-881.

12. Huffman ML, King J, Reichelt M. Equality for whom? Organizational policies and the gender gap across the German earnings distribution. ILR Review. 2017;70(1):16-41.

13. Bosch $\mathrm{G}$, Weinkopf $\mathrm{C}$. Reducing wage inequality: The role of the state in improving job quality. Work and Occupations. 2017;44(1):68-88.

14. Ejaz M. Determinants of female labor force participation in Pakistan an empirical analysis of PSLM (2004-05) micro data. The Lahore Journal of Economics. 2007;12(1):203-235.

15. Ehsan S. Female Labor Force Participation, Its Determinants and Effect on GDP in Pakistan. India: Master's thesis, Eastern Mediterranean University (EMU); 2015. 63 p. 